\title{
Obsesif Kompulsif Bozukluk ve Araknoid Kist: Bir Olgu Sunumu
}

\author{
Obsessive Compulsive Disorder and Arachnoid Cyst: A Case Report \\ Fatih Özdemir ${ }^{1}$ iD, Çiçek Hocaoğlu ${ }^{1}$
}

1 Psikiyatri Ana Bilim Dalı, Recep Tayyip Erdoğan Üniversitesi Tıp Fakültesi, Rize/Türkiye

\section{ÖZET}

Araknoid kistler araknoid membrandan kaynaklanan benign yer kaplayıcı lezyonlardır. Çoğu konjenitaldir ve çocukluk döneminde rastlantısal olarak tanı alır. Klinikte hiç semptom vermeyebileceği gibi çok çeşitli nöropsikiyatrik semptomlarla birlikte olabilir. Bu çalışmada psikiyatri kliniğimize son günlerde artan ajitasyon, uykusuzluk, işitsel ve taktil varsanılar nedeniyle yakınları tarafından getirilen; yapılan görüşmelerde şüphe obsesyonları ve kontrol etme kompulsiyonları olduğu fark edilen, kraniyal görüntülemesinde araknoid kist saptanan 43 yaşındaki kadın hastanın mevcut klinik durumu literatür bilgileri ışığında tartışılmıştır.

Anahtar Kelimeler: araknoid kist, obsesif kompulsif bozukluk, tanı, tedavi

\section{ABSTRACT}

Arachnoid cysts are benign space-occupying lesions originating from the arachnoid membrane. Most of them are congenital and are diagnosed randomly in childhood. It may present no symptoms at all in the clinic and may present with a variety of neuropsychiatric symptoms. In this study we discussed a patient who recently brought by relatives to our psychiatry clinic with agitation, insomnia, auditory and tactile hallucinations in the light of the literature. During the clinical interview with 43 years old female patient, who had arachnoid cyst in cranial imaging was determined, suspicion obsessions and control compulsions were realized.

Keywords: arachnoid cyst, obsessive compulsive disorder, diagnosis, treatment

\section{GiRiş}

Araknoid kistler nadir görülen, iyi huylu yer kaplayıcı lezyonlardır (1). Çoğu konjenital olmakla birlikte travma, malignite, enfeksiyon gibi durumlara ikincil olarak da gelişebilirler. Santral sinir sisteminin hemen her yerinde özellikle kraniyal fossa, Sylvian fissür, suprakolliküler bölge, vermis, serebropontin köşe, sellar ve suprasellar alanlarda görülebilirler (2). Nöropsikiyatrik belirtilerle kendilerini gösterebilecekleri gibi asemptomatik de olabilirler. Araknoid kistler ile psikiyatrik bozukluklar arasındaki ilişki tam olarak bilinmemektedir. Bu güne kadar çoğunluğu olgu sunumu olarak hazırlanan çalışmalarda araknoid kist ile psikotik bozukluklar, bipolar bozukluk birlikteliğine dikkat çekilmiş olup, diğer ruhsal bozukluklar (örneğin obsesif kompulsif bozukluk (OKB)) ile ilişkisi ise, az sayıdaki çalışmada ele alınmıştır (2-8). Bu nedenle araknoid kistler ile ruhsal bozukluk eş tanısını inceleyen her çalışma konunun daha iyi anlaşılmasını yardımcı olacaktır.

Bu çalışmada psikiyatri kliniğimize OKB belirtileri ile başvuran, beyin nörogörüntülemesinde araknoid kist saptanan kadın hastanın klinik bulguları konu ile ilgili diğer çalışmalarının sonuçları ile tartışılarak mevcut literatüre katkı sunulması amaçlanmıştır.

\section{OLGU}

Bayan B, 43 y, bekar, ilkokul mezunu, ev hanımı, ailesiyle birlikte yaşıyor.

Son 2 haftadır sinirlilik, uykusuzluk, kulağına sesler gelmesi, görüntüler görme, sürekli aynı soruları sorma, oturduğu yerde herhangi bir şeyin olup/olmadığından emin olamama, sürekli oturduğu yeri kontrol etme yakınmaları ile ailesi tarafından psikiyatri polikliniğimize getirildi. Illk yakınmalarının 2014 yılında insanlardan uzaklaşma, içe kapanma, evden çıkmak istememe, temizlik ile ilgili uğraşılarında artma, banyoda uzun sürme kalma şeklinde başladığı ve bu yakınmalarının giderek arttığı öğrenilen hasta, ailesi tarafından bir psikiyatra götürülmüş. Essitalopram 10mg/gün, risperidon $2 \mathrm{mg} /$ gün tedavisi önerilen hasta ilaçlarını kullanmamış ve kontrollerine gitmemiş. 2014-2016 yılları arası herhangi bir hastane başvurusu ve tedavi görme öyküsü olmayan hastanın yakınmaları aynı şekilde devam etmiş. Benzer yakınmalar ile 2017 yılında psikiyatri polikliniğimize başvuran hastaya

Yazışma Adresi/Address for Correspondence: Çiçek Hocaoğlu, MD, Recep Tayyip Erdoğan Üniversitesi Tıp Fakültesi Psikiyatri Anabilim Dalı, Rize/Türkiye E-Posta/E-Mail: cicekh@gmail.com || Tel: +90 5332779267

Received/Geliş Tarihi: 11.05.2020 || Accepted/Kabul Tarihi: 30.08.2020

Bu Eser Creative Commons Atıf-Gayriticari 4.0 Uluslararası Lisansı İle Lisanslanmıştır. This work is licensed under a Creative Commons

Attribution-NonCommercial 4.0 International License (CC BY-NC 4.0). 
yatarak tedavi görmesi önerilmiş. Ancak, hasta yatarak tedavi görmeyi, ilaç kullanmayı kabul etmemiş. Son 15 gün içerisinde yakınmalarında alevlenme olan hasta görüşme sırasında kendisine küfür eden sesler duyduğunu, kadın vücutları gördüğünü, vücuduna dokunulduğunu hissettiğini, kendisi üzerinde tanımadığı kişiler tarafından deney yapıldığını belirtti. İçinde kendisi ile yaşayan birisi olduğunu hissettiği için banyo yapmadığını ifade eden hasta sandalyenin uç kısmında oturuyor, tekrarlayıcı biçimde oturduğu yeri kontrol ediyordu. Bu davranışın nedeni sorgulandı̆̆ında bir şeyin üstüne oturduğuna dair şüphe duyduğunu ve kontrol etme intiyacı hissettiğini belirtti. ileri tetkik ve tedavi amacıyla servisimize kabul edilen hastanın öz ve soy geçmişinde bir özellik tanımlanmadı. Sigara, alkol ve diğer psikoaktif madde kullanım öyküsü olmayan hastanın, hastalanmadan önce sessiz ve içe kapanık bir kişiliğe sahip olduğu öğrenildi. Nörolojik muayene ve diğer sistem muayeneleri ile hemogram, endokrin, biyokimyasal tetkiklerinde patolojik bulgu saptanmadı.

Ruhsal Durum Muayenesi: Yaşında görünümde, giyimi sosyoekonomik düzeyiyle uyumlu, öz bakımı azalmıştı. Bilinç açık, yönelim tamdı. Dikkatte çelinebilirlik artmıştı. Bellek korunmuştu. Disforik duygudurum ve duygulanımda kısıtlılık mevcuttu. Konuşmaya isteksizdi, göz teması kuruyordu. Son 15 gündür aralıksız devam eden İşitsel, görsel ve taktil varsanıların olduğu saptandı. Soyut düşünce yetisi korunmuştu. İçgörüsü yoktu. Gerçeği değerlendirme yetisi bozulmuştu. Düşünce hızı artmıştı. Çevresel düşünce, düşünce uçuşması mevcuttu. Çağrışımların düzeni bozulmuştu. Düşünce içeriğinde son 2 haftadır aralıksız devam eden perseküsyon sanrıları, simetri ve şüphe obsesyonları vardı. Dışa vuran davranışlarda hareketlerde artış, düzenleme ve kontrol etme kompulsiyonları mevcuttu.

Klinik Seyir: Psikiyatrik değerlendirme sonrası hastaya DSM5'e göre şizofreni, çoğul dönemler, o sırada akut dönemde ve OKB içgörüsü yok/sanrısal inanışlar tanıları ile fluoksetin 20mg/gün, olanzapin 10mg/gün tedavisi başlandı. Geç ve atipik başlangıç özellikleri nedeniyle tetkik edilen işlevselliği oldukça bozulan hastanın beyin Manyetik Rezonans (MR) görüntülemesinde beyin sapı, her iki serebellar ile IV. ventrikül, III. ve lateral ventriküllerinin genişliği doğal, sağ frontal bölge sentrum semiovale düzeyi lateralde yaklaşık $2,5^{*} 1,5 \mathrm{~cm}$ boyutlu BOS ile izointens ekstraaksiyel lezyon araknoid kist olarak raporlandı (Resim
1-2). Hastanın önceki hastane kayıtları incelendi ve eski tarihli radyolojik incelemesinin olmadığı saptandı. Ailesi ile görüşülerek 2014 yılı öncesi çekilmiş bir kraniyal MR'sinin olup olmadığı sorgulandı ve bu tür bir incelemenin daha önce hiç yapılmadığı öğrenildi. Bu nedenle kistin boyutunun değişip değişmediği konusunda bir karşılaştırma yapılamadı. Elektro ensefalografi (EEG)'de patolojik bulguya rastlanmadı. Araknoid kist nedeniyle nöroşirurji konsültasyonu istenen hastaya nörolojik bulgu olmaması nedeniyle poliklinik takibi önerildi. Kısa Psikiyatrik Değerlendirme Ölçeği(BPRS) 17, Yale-Brown Obsesyon ve Kompulsiyon Değerlendirme Ölçeği (Y-BOCS) simetri ve kuşku obsesyonları, düzeltme ve kontrol etme kompulsiyonları başta olmak üzere 34, Pozitif Belirtileri Değerlendirme Ölçeği(SAPS) 54, Negatif Belirtileri Değerlendirme Ölçeği(SAPS) 5 puan olarak değerlendirildi. Illk günlerde servis çalışanları ve diğer hastalarla iletişim kurmayan, etkinliklere katımayan, gün içinde odasında kalmayı tercih eden hastanın ilerleyen günlerde sosyal katılımının arttığı, yapılan klinik görüşmelerde yapısal düşünce bozukluklarının, varsanıların, OKB belirtilerinin azaldığı izlendi. Hasta yatışının 14. gününde fluoksetin 20mg/gün, olanzapin 15 mg/gün tedavisi önerilerek kısmi salah haliyle ailesinin isteği üzerine taburcu edildi. On gün sonra poliklinik kontrolünde değerlendirilen hasta işitsel varsanılarda değişme olmadığını, görsel, taktil varsanılarda belirgin azalma olduğunu, simetri obsesyonlarında kısmi, şüphe obsesyonları ve kontrol etme kompulsiyonlarında belirgin düzelme olduğunu ifade etti. Düşünce hızı normaldi, çevresel düşünce ilk başvuruya kıyasla azalmıştı. Hastanın yakını da hastanın evdeki işleyişe katıldığını, uykularının düzenli olduğunu, dışarı çıkıp alışveriş yapabildiğini, tedavisini düzenli kullandığını belirtti. Uygulanan psikometrik değerlendirmelerde BPRS 10, YBOCS 21, SAPS 41, SANS 4 puan olarak değerlendirildi. Olanzapin $15 \mathrm{mg} /$ gün, fluoksetin $40 \mathrm{mg} /$ gün olarak tedavisi düzenlenen hastanın halen ayaktan poliklinik kontrolleri devam etmektedir. Olgu yazımı öncesi hastadan ve yakınından yazılı onamı alındı.

\section{SONUÇ}

Araknoid kistlere ait klinik belirtiler kistin yerleşim yeri ve büyüklüğüne göre değişiklik gösterir. Bazı araknoid kistler oldukça küçük ve yerleşim yeri nedeni ile hiç bir belirtiye neden olmaz iken, bazıları şiddetli geçmeyen baş ağrısı, 
epileptik nöbet ve hidrosefaliye neden olabilir $(9,10)$. Nörolojik belirtilerin yanı sıra yerleşim yerleri ile de ilişkili olarak çok sayıda psikiyatrik belirtiye de eşlik edebilirler. Psikotik belirtiler başta olmak üzere aleksitimi, hiperaktivite, deliryum, çökkünlük, varsanılar, perseküsyon sanrıları, uykusuzluk, sinirlilik, demans, organik mental bozukluk, anoreksiya nervoza, katatoni, intihar girişimleri, saldırgan davranış gibi çok çeşitli psikiyatrik belirtinin araknoid kist ile birlikte görülebileceği bildirilmiştir(11). Beyinde özellikle sol frontal lobda yer kaplayan lezyonların bilinç bozuklukları, bilişsel yıkıma neden oldukları bilinmektedir. Başka bir deyişle sol frontal bölgede yer kaplayan kist, tümör gibi oluşumlar sağ frontal bölgeye göre daha fazla bilişsel bozulmaya yol açar. Sağ frontal bölge yerleşimli lezyonlarda ise, duygudurum değişiklikleri, çökkünlük, öfori, obsesif belirtiler, anksiyete gibi psikiyatrik belirtiler izlenir (12). Olgumuzda sağ frontal bölgede yer alan araknoid kiste obsesif belirtilerin eşlik etmesi bu bulgularla uyumludur.

Araknoid kistlerin, psikiyatrik bozuklukla ilişkisiz gelişmesi ve herhangi bir belirtiye eşlik etmeksizin, tesadüfi bir bulgu olması da olasıdır. Ancak, olgumuzda hastalığın geç başlangıçlı olması, ailede psikiyatrik hastalık öyküsünün bulunmaması olgumuzdaki psikotik ve obsesyonel belirtilerin araknoid kistin etkisiyle ortaya çıkmış olabileceğini düşündürmektedir. Daha önce yapılan çalışmalarda da psikiyatrik belirtilerin geç başlangıçlı olduğu, hastalarda izlenen OKB belirtilerinin çalışmamızda bildirilen olgu ile benzer özellikte ve sanrısal inançların ön planda olduğu belirtilmiştir $(8,13)$. Olgumuzda da olduğu gibi psikotik belirtiler ve OKB belirtilerinin birlikte görülmesi günümüze kadar olan dönemde klinisyenlerin dikkati çekmiştir. Şizofreninin pozitif, negatif ve bilişsel belirtilerine ek olarak anlamlı OKB belirtileri gösteren hastaları kapsayan şizo-obsesif bozukluk tanımı önerilmiştir (14). Ancak, şizo-obsesif bozukluğun şizofreni ve OKB'den farkı ya da ayrı bir tanı olup/olmadığı tam olarak açıklanabilmiş değildir. Tedavi yaklaşımları açısından da daha önce bildirilen olgu örneklerinde fluoksetin ve olanzapin kullanımı ile kısmi tedavi yanıtların alındığını bildirilmiş olması çalışmamızın bulguları ile uyumludur $(8,13)$. Araknoid kist ve psikiyatrik belirtilerin birlikte görüldüğünü bildiren çalışmalar olmasına karşın araknoid kist ve içgörüsü olmayan OKB eş tanısı ile ilgili çok az sayıda çalışma mevcuttur (15).
Geç başlangıçlı, aile öyküsü bulunmayan, nörolojik bulgu saptanmayan psikiyatrik yakınmalar söz konusu olduğunda nöro-görüntüleme yöntemlerinin kullanılması önemli olup; mevcut yakınmaların yapısal beyin lezyonlarıyla ilişkisi göz önünde bulundurulmalı ve tıbbi nedenler araştırılmalıdır. Çalışmamızın geç başlangıçlı atipik psikiyatrik belirtilerle başvuran araknoid kisti bulunan hastalarda nörogörüntüleme yöntemlerinin önemini vurgulayıcı yönüyle literatüre katkı sağlayacağını düşünmekteyiz.

Etik; Bu yazıda sunulan olgu için sunulan bilgilerin akademik amaçlı kullanımı hakkında detaylı bilgileri de içeren imzalı "Bilgilendirilmiş onam formu" alınmıştır.

Ethics; For the case presented in this article, a signed "informed consent form" was obtained, which includes detailed information about the use of the information presented for academic purposes.

Yazar katkı durumu; Olgunun tanı ve takip süreci; FÖ, ÇH, tedavi süreci; FÖ, ÇH, Literatür taraması; FÖ, ÇH, yazım aşaması; FÖ, ÇH

Author contribution status; The concept of the study; design; FÖ, ÇH, literature review; FÖ, ÇH, collecting and processing data; FÖ, ÇH, statistics; FÖ, ÇH, writing phase; FÖ, ÇH

Yazarlar arasında çıkar çatışması yoktur.

The author declares no conflict of interest.

Finansal Destek: yoktur / Funding : none

doi: https://doi.org/10.33713/egetbd.735543

\section{KAYNAKLAR}

1. Baquero GA, Molero P, Pla J, Ortuño F. A schizophrenia-like psychotic disorder secondary to an arachnoid cyst remitted with neurosurgical treatment of the cyst. Open Neuroimag J. 2014; 21:1-

2. da Silva JA, Alves A, Talina M, Carreiro S, Guimarães J, Xavier M. Arachnoid cyst in a patient with psychosis: Case report. Ann Gen Psychiatry. 2007; 6:1-

3. Khan AH, Ahmed SE. Arachnoid cyst and psychosis. Cureus. 2017; 21;9: e1707.

4. Wu YY, Shen YC. Delusions of control in a case of schizophrenia coexisting with a large cerebellar arachnoid cyst. Ci Ji Yi Xue Za Zhi. 2017;29:115-1

5. Harmanci H, Gokbakan AM. A bipolar disorder patient with arachnoid cysts: A case report. J Clin Psy. 2013; 16: 53-56.

6. Akar H, Yazar S, Özmen E, Keskinkılıç C, Eradamlar N, Alpkan L. Nöropsikiyatrik semptomlarla seyreden araknoid kist olgusu. Düşünen Adam Dergisi. 2004; 17: 238-243. 
7. Bakim B, Karamustafalioglu KO,Ozalp G, et al. Arachnoid cyst and bipolar disorder: A case report Journal of Mood Disorders. 2012;2:70-

8. 8. Hegde A, Ghosh A, Grover S, Kumar A, Chabbra R. Arachnoid cyst masquerades as late onset obsessivecompulsive disorder. Gen Hosp Psychiatry. 2014;36:125.e7-

9. Galarza M, López-Guerrero AL, Martínez-Lage JF. Posterior fossa arachnoid cysts and cerebellar tonsillar descent: short review. Neurosurg Rev. 2010;33:305-314.

10. Ammar A, Alojan AA, Turkistani AN, Alrayes MM. Spontaneous Regression of Pineal Region Arachnoid Cyst: A Case Report and Review of Literature. Asian J Neurosurg. 2020; 15:155-1

11. Seddighi A, Akbari ME, Seddighi AS, Nikouei A. Psychological consideration in patients with cerebral gliomas candidates for intra-operative radiation therapy based on tumor location. Hell J Nucl Med. 2017;20 Suppl:20-24.

12. Gjerde PB, Litleskare $S$, Lura NG, et al. Anxiety and Depression in Patients with Intracranial Arachnoid Cysts-A Prospective Study. World Neurosurg. 2019;132:e645-e6

13. 13.Tonna M, Ottoni R, Ossola P, De Panfilis C, Marchesi C. Late-onset obsessive-compulsive disorder associated with left cerebellar lesion. Cerebellum. 2014;13:531-5

14. Poyurovsky M, Zohar J, Glick I, et al. Obsessive-compulsive symptoms in schizophrenia: implications for future psychiatric classifications. Compr Psychiatry. 2012;53:480-483.

15. Biswas PS, Sen D, Chaudhary S. Middle cranial fossa arachnoid cyst presenting with obsessive compulsive behaviour associated with psychosis - two cases. Afr J Psychiatry (Johannesbg). 2012; 15:59- 